\title{
Adsorption of volatile organic compounds using activated carbon fiber filter in the automobiles
}

\author{
Hyung Suk Moon ${ }^{1, \$}$, In Soo Kim ${ }^{1}$, Sin Jae Kang ${ }^{2}$ and Seung Kon Ryu ${ }^{2}$ \\ ${ }^{1}$ Civil and Environmental Engineering, Korea Maritime and Ocean University, Busan 606-791, Korea \\ ${ }^{2}$ Korea Institute of Carbon Convergence Technology, Jeonju 561-844, Korea
}

\author{
Article Info \\ Received 13 May 2014 \\ Accepted 14 June 2014 \\ *Corresponding Author \\ E-mail: moonhs99@naver.com
}

\section{Open Access}

DOI: http://dx.doi.org/

10.5714/CL.2014.15.3.203

This is an Open Access article distributed under the terms of the Creative Commons Attribution Non-Commercial License (http://creativecommons.org/licenses/ by-nc/3.0/) which permits unrestricted non-commercial use, distribution, and reproduction in any medium, provided the original work is properly cited.

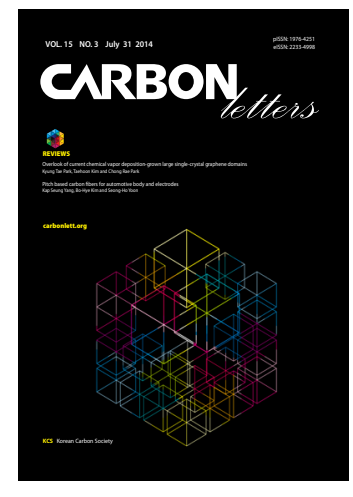

http://carbonlett.org

pISSN: 1976-4251

elSSN: 2233-4998

Copyright $\odot$ Korean Carbon Society

\begin{abstract}
The adsorption of volatile organic compounds (VOCs) was carried out using an activated carbon fiber (ACF) filter in an automobile. The adsorption capacities of formaldehyde, toluene, and benzene on an ACF filter were far better than those of a polypropylene (PP) mat filter and combined (PP+activated carbon) mat filter by batch adsorption in a gas bag. In a continuous flow of air containing toluene vapor through an ACF packed bed, the breakpoint time was very long, the length of the unused bed was short, and sharp "S" -type breakthrough curve was plotted soon after breakpoint, showing a narrow mass transfer zone of toluene on the ACF. The adsorption amount of toluene on the ACF filter was proportional to the specific surface area of the ACF; however, the development of mesopores 2-5 nm in size on the ACF was very effective with regard to the adsorption of toluene. The ACF air clarifier filter is strongly recommended to remove VOCs in newly produced automobiles.
\end{abstract}

Key words: adsorption, volatile organic compounds, activated carbon fiber filter, breakpoint, mesopores

\section{Introduction}

Today, humans spend a lot of time in their automobiles. Volatile organic compounds (VOCs), which are generated from the interior materials of an automobile, have a significant impact on human health; thus, the need to prevent them from penetrating into the human body has increased. The main VOCs emitted from the interior materials of new automobiles include formaldehyde, toluene, benzene, styrene, xylene, ethylene, and acetaldehyde. Kim and Lee [1] reported that toluene among the indoor air pollutants of newly delivered automobiles was approximately $285 \mathrm{mg} / \mathrm{m}^{3}$ on average; thereby causing fatigue, headaches, eye irritation, agitation, insomnia, and a loss of appetite, walking difficulty, nausea and death at high concentrations. Kouichi and Shinichi [2] removed a sheet made out of vinyl chloride within one week from a newly delivered Japanese automobile and measured the emission amounts of VOCs. He reported that various types of chemicals were detected from luxury automobiles, with toluene on average at $2429 \mu \mathrm{g} / \mathrm{m}^{3}$ and the total amount of VOCs was $9850 \mu \mathrm{g} / \mathrm{m}^{3}$. Lee et al. [3] measured the VOC properties generated from the interiors of Korean compact and mid-size sedans and reported in particular that an excessive amount of toluene was generated from the thermoplastic polyolefin (TPO) skin from the door trim armrest surface. At present, polypropylene (PP) non-woven and combined ( $\mathrm{PP}+$ activated carbon $[\mathrm{AC}]$ ) non-woven filters are commercially being used in automobiles; however, they are known to be ineffective for removing VOCs. Son et al. [4] reported that AC shows good performance for the adsorption of VOCs, but its adsorption speed for VOCs is slow due to the existence of a macropore structure. Moreover, they often cannot be recycled. Therefore, the development of new types of adsorbents that can replace AC is necessary.

Activated carbon fiber (ACF) is a new type of adsorbent. All of the pores developed on the ACF are micropores and are mutually connected from the surface to the internal side; thus, 
the specific surface area of this type of fiber is very large and the mass transfer resistance is very low. Its adsorption speed of VOCs is known to be 100 times or more than that of $\mathrm{AC}$ [5]. Furthermore, the shape is either woven or non-woven; thus, it would be appropriate to apply it as a face filter. Son et al. [4], Baek et al. [6], and Kim and Chang [7] have studied the toluene adsorption characteristics with ACF packed beds. Byun et al. [8] reported the adsorption and desorption behaviors of toluene and isopropyl alcohol by utilizing an ACF, and Park et al. [9] also studied the characteristics of benzene adsorption and the desorption features of ACF. However, all of them reported the ACF adsorption and desorption capacities for VOCs. Moon et al. [10] reported that the removal capacity of PM2.5 on an ACF filter in an automobile was slightly better than those of commercial automobile filters. However, there have been few reports on the removal mechanisms of contaminants in automobiles. Moreover, scant data exists on applications of ACFs as air clarifier filters.

Therefore, the purpose of this study is to investigate the adsorption of VOCs using ACF filters in newly produced automobiles. To this end, first, an ACF non-woven filter and two other commercial air clarifier filters were put into a batch gas bag to compare the adsorption capacity of VOCs, and second, the toluene adsorption behaviors of ACF were investigated under a continuous flow of toluene vapor containing air through an ACF packed bed under several conditions.

\section{Experimental}

\subsection{Materials}

Non-woven ACF (MD-1100, Sutong Co., China, and KF-1500, Toyobo, Japan) filters were prepared. Two types of non-woven filters (PP, $\mathrm{PP}+\mathrm{AC}$ ) commercially used in automobiles were also prepared. ACF filters were placed in a desiccator after being dried for $24 \mathrm{~h}$ in an oven and were maintained at $200^{\circ} \mathrm{C}$. The pore size distributions of the as-received ACFs were measured by Brunauer-Emmett-Teller (BET) specific-surface-area measuring equipment (BELSORPmax, Japan). The formaldehyde, benzene, and toluene used in this study were reagent-grade materials (Aldrich Co., $>99.5 \%$ ).

\subsection{Methods}

The adsorption capacities of VOCs for the three types of filters were measured by a tube-type gas detector in a batch gas bag following the KSI method [11]. The three types of filters (76 g ACF filter, $40 \mathrm{~g}$ PP filter, and $127 \mathrm{~g} \mathrm{PP}+\mathrm{AC}$ ) were put into a batch gas bag and were maintained at a constant temperature. Formaldehyde, toluene, and benzene were injected into the $5 \mathrm{~L}$ gas bag at initial concentrations of 15,20 , and $20 \mathrm{ppm}$, respectively. Two hours later, each concentration was detected and the adsorption rate was calculated by the following Eq. (A):

$$
\text { Adsorptionrate }(\%):\left(\mathrm{C}_{\mathrm{b}}-\mathrm{C}_{\mathrm{s}}\right) / \mathrm{C}_{\mathrm{b}} \times 100
$$

$\mathrm{C}_{\mathrm{b}}$ : Blank, concentration of experimental gas that remained $\in$ the experimental gas bag after 2 hours

$\mathrm{C}_{\mathrm{s}}$ : Specimen, concentration of experimental gas that remained $\in$ the experimental gas bag after 2 hours

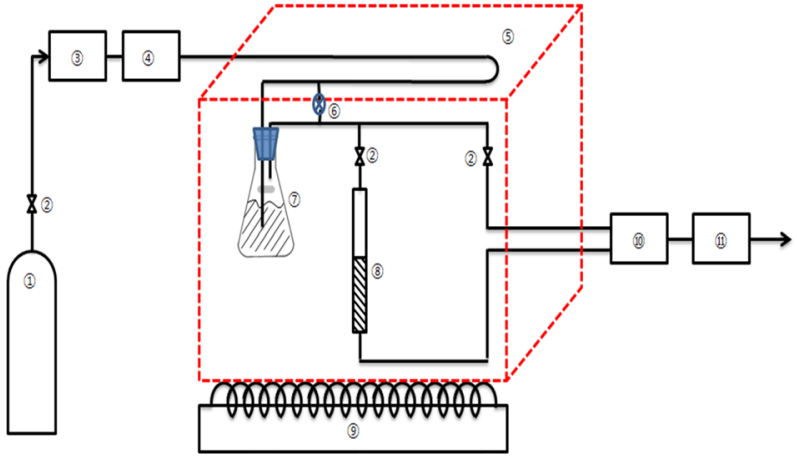

Fig. 1. Schematic diagram of the experimental apparatus: (1) air reservoir, (2) valve, (3) dryer, (4) mass flow controller, (5) temperature control chamber, (6) flow meter (7) volatile organic compounds (VOCs) generator, (8) activated carbon fiber packed bed, (9) heat and temperature controller, (10) VOCs detector, and (11) computer.

The continuous adsorption behaviors of toluene through the ACF packed bed were assessed with the experimental apparatus shown in Fig. 1. The main parts of the apparatus contained a mass flow controller (MFC, (4)) of air, a toluene vapor generator (7) and the ACF packed bed (8) in a constant-temperature chamber (5), as well as analysis units (10) (11) for the toluene vapor in effluent. A flask was completely filled with liquid toluene (7) and vapor was generated by dry air. A glass tube adsorption bed $(15$ and $30 \mathrm{~mm}$ in diameter and $200 \mathrm{~mm}$ in length) was packed with ACF. Dried air was supplied at $2 \mathrm{~L} / \mathrm{min}$ by a MFC. This air circulated for a long time in the temperature-controlled chamber, and some proportion of the air was directly injected into the toluene-generating container while another part of the air was separated by a flow meter (6) and mixed with the air containing the toluene vapor, such that the concentration of toluene in the air could be controlled before entering the ACF packed bed. The chamber was maintained at $25^{\circ} \mathrm{C}$ or $35^{\circ} \mathrm{C}$. When the air flow rate to the toluene-containing flask was maintained at $1 \mathrm{~L} / \mathrm{min}$., the initial concentrations $\left(\mathrm{C}_{\mathrm{o}}\right)$ of toluene to be inserted into the ACF packed bed were approximately $195-205 \mathrm{ppm}\left(25^{\circ} \mathrm{C}\right)$ and $390-405 \mathrm{ppm}\left(35^{\circ} \mathrm{C}\right)$. Therefore, the initial concentrations were fixed at $200 \mathrm{ppm}\left(821.4 \mathrm{mg} / \mathrm{m}^{3}\right)$ and $400 \mathrm{ppm}$, respectively, by controlling the separated air flow with a flow meter (6). For the connections of each device, a quarter-inch Teflon tube was utilized and glass wool with a thickness of 3-mm was inserted above the bottom of the ACF packing bed. The experimental conditions for the continuous adsorption behaviors are summarized in Table 1.

The toluene concentration in the effluent was measured by a VOC concentration measurement device (Indoor Air Quality Monitor, IAQRAE, USA, 0.01-500 ppm), as shown in Fig. 1 , and was plotted by breakthrough curves. The break point $\left(t_{b}\right)$ was selected at $5 \%$ of the initial toluene concentration. The break point time, the maximal adsorption capacity $\left(\mathrm{W}_{\mathrm{e}}\right)$, and the valid adsorption rate at the break point were obtained from breakthrough curves under several experimental conditions. The adsorption capacity was analyzed in relation to the pore size distribution of the ACFs. The adsorption mechanism of toluene by the ACF was analyzed by inserting the adsorption behaviors and data into the well-known Yoon and Nelson equation [12]. 
Table 1. Experimental conditions

\begin{tabular}{ccccccc} 
No. & $\begin{array}{c}\text { ACF packing } \\
(\mathrm{g})\end{array}$ & $\begin{array}{c}\text { Bed diameter } \\
(\mathrm{mm})\end{array}$ & $\begin{array}{c}\text { Bed height } \\
(\mathrm{mm})\end{array}$ & $\begin{array}{c}\text { Packing density } \\
\left(\mathrm{g} / \mathrm{cm}^{3}\right)\end{array}$ & $\begin{array}{c}\text { Temperature } \\
\left({ }^{\circ} \mathrm{C}\right)\end{array}$ & Kind of ACF \\
\hline$(1)$ & 2.2 & 15 & 70 & 0.1779 & 25 & MD-1100 \\
$(2)$ & 2.2 & 15 & 70 & 0.1779 & 25 & KF-1500 \\
$(3)$ & 2.2 & 15 & 140 & 0.0889 & 25 & MD-1100 \\
$(4)$ & 4.4 & 15 & 140 & 0.1779 & 25 & MD-1100 \\
$(5)$ & 2.2 & 30 & 35 & 0.0889 & 25 & MD-1100 \\
$(6)$ & 2.2 & 15 & 70 & 0.1779 & 35 & MD-1100 \\
\hline
\end{tabular}

ACF: activated carbon fiber.

\section{Table 2. Removal efficiency of VOCs by three types of filters (\%)}

\begin{tabular}{cccc} 
VOCs & PP filter & $(\mathrm{PP}+\mathrm{AC})$ filter & ACF filter \\
\hline Formaldehyde & 20.0 & $>99.3$ & $>99.3$ \\
Toluene & 5.0 & 78.9 & $>97.5$ \\
Benzene & 0.0 & $>97.5$ & $>97.5$ \\
\hline
\end{tabular}

VOCs: volatile organic compounds, PP: polypropylene, AC: activated carbon.

\section{Results and Discussion}

\subsection{VOCs adsorption of various filters in a gas bag}

The adsorption capacities of VOCs by three non-woven filters in a batch gas bag were measured by a gas detecting tube [11], as summarized in Table 2. The PP non-woven filter could only remove $20 \%$ of the initial amount of formaldehyde, whereas it was not able to remove any of the toluene or benzene. For the $(\mathrm{PP}+\mathrm{AC})$ non-woven filter, the removal rates of formaldehyde and benzene we re good; however, the removal rate of toluene was not as good, as it left $78.9 \%$ of the initial concentration. On the other hand, the ACF non-woven filter removed more than $97.5 \%$ of all VOCs used in the experiment. From a previous report [10], the ACF filter shows relatively good removal capacity of microparticles (PM2.5) and carbon dioxide in automobiles. Therefore, ACF can be used as a promising adsorbent for the removal of contaminants in automobiles. However, the quantitative removal capacities of the VOCs are needed in accordance with time and other variables. Thus, follow-up experiments were performed to investigate the removal capacity of toluene from an air flow containing toluene vapor through an ACF packed bed.

measured by FITI Testing \& Research Institute [11].

\subsection{Toluene adsorption capacity of different types of ACFs}

Fig. 2 shows the breakthrough curves of toluene on the ACF bed. Both (1) the MD-1100 ACF and (2) the KF-1500 ACF show

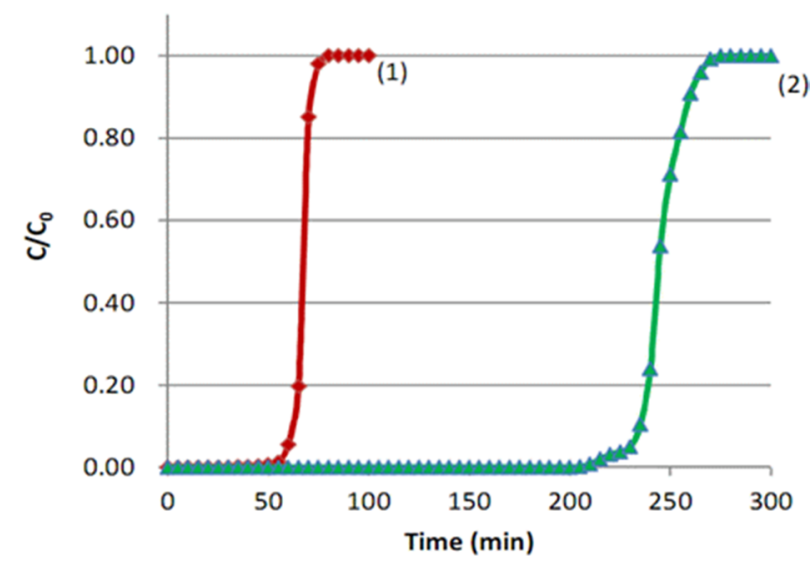

Fig. 2. Breakthrough curves of toluene on the activated carbon fiber packing bed at $25^{\circ} \mathrm{C}: \mathrm{Q}=2 \mathrm{~L} / \mathrm{min}, \mathrm{Co}=200 \mathrm{ppm}, \mathrm{M}=2.2 \mathrm{~g}, \varphi=15 \mathrm{~mm}$ : (1) MD-1100 and (2) KF-1500.

rapidly increasing curves after the break point; indicating that toluene adsorption progresses in a narrow mass-transfer zone [13] as most of the pores which developed on the surface of ACF are micropores. For this reason, toluene adsorption occurred very rapidly according to the micropore filling theory of Dubinin [14]. When setting $5 \%$ of the initial concentration as the break point $\left(t_{b}\right)$, break point times of the two ACFs were $61 \mathrm{~min}$ and $230 \mathrm{~min}$. The break point of KF-1500 was 3.76 times longer than that of MD-1100, because the specific surface area of KF-1500 was larger than that of MD-1100. In general, the KF-1500 on the market has a specific surface area of $1500 \mathrm{~m}^{2} / \mathrm{g}$, whereas MD-1100 has a specific surface area of $1100 \mathrm{~m}^{2} / \mathrm{g}$. It appears that the specific surface area of KF-1500 was 1.36 times greater than that of MD1100. However, the break point time of KF-1500 was far longer than that of MD-1100, which suggested a need to review the micropore size distribution more thoroughly. Therefore, the adsorption isotherms of two ACFs were reanalyzed.

Fig. 3 shows the nitrogen adsorption isotherms of two ACFs at $77 \mathrm{~K}$, and Table 3 is the BET characteristics of the two ACFs Both ACFs show rapid nitrogen adsorptions in a low range of the relative pressure $(\mathrm{P} / \mathrm{Po})$, reaching a plateau and showing typical Type 1 isotherm characteristics. In other words, the pores developed on the surface are mostly micropores. The total amounts of nitrogen adsorption at the plateau were about $300 \mathrm{~cm}^{3} / \mathrm{g}$ and 470 
$\mathrm{cm}^{3} / \mathrm{g}$, respectively. Therefore, the specific surface areas of the two ACFs were $1690 \mathrm{~m}^{2} / \mathrm{g}$ and $1090 \mathrm{~m}^{2} / \mathrm{g}$, respectively. The specific surface area of KF-1500 was 1.55 times larger than that of MD-1100, which is coincident with the total pore volume ratio.

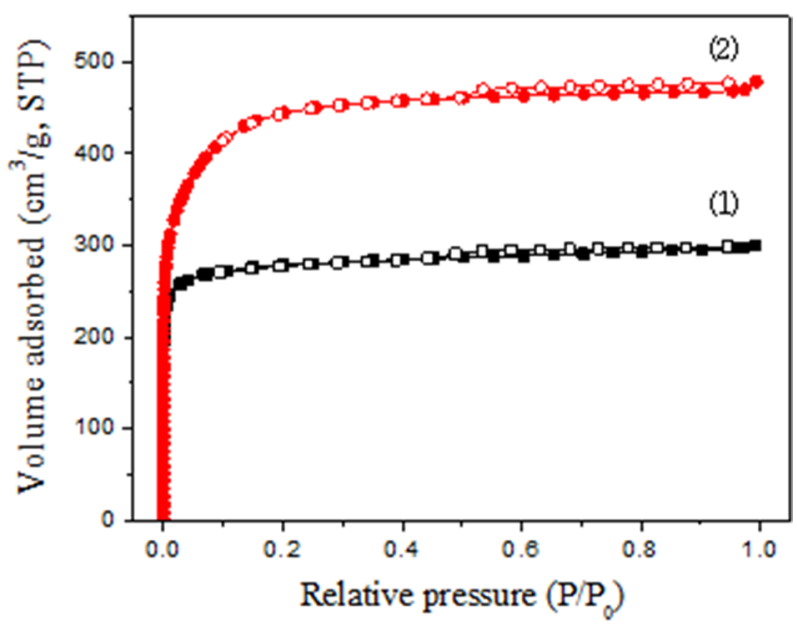

Fig. 3. Adsorption isotherms of nitrogen: (1) MD-1100 and (2) KF-1500.

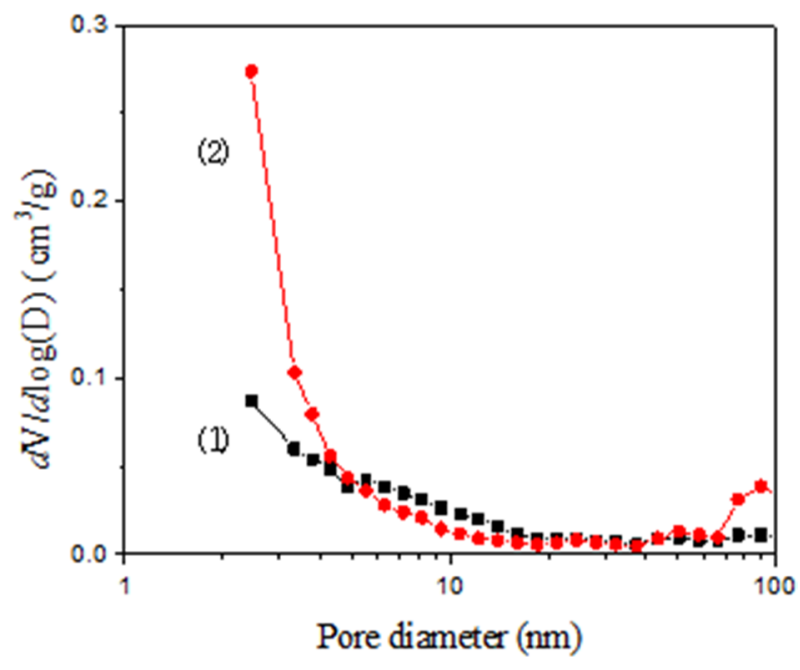

Fig. 4. Distribution of mesopores measured according to the BarretJoyner-Halenda equation: (1) MD-1100 and (2) KF-1500.
The micropore volume of KF-1500 was 1.41 times larger. However, it is important to note that the mesopore volume of KF-1500 was 3.76 times larger than that of MD-1100. The ratio of these mesopores was equivalent to the ratio of the adsorption capacity at the break point time. Therefore, the adsorption of toluene depends on the number of mesopores. On the other hand, the pore size distributions of ACFs should be more carefully studied. Fig. 4 shows the distribution of mesopores obtained from the Barret-Joyner-Halenda (BJH) equation. The mean pore diameter of KF-1500 is $1.75 \mathrm{~nm}$, which is similar to MD-1100 at $1.70 \mathrm{~nm}$; however, the pore size of MD-110 was widely distributed from $1.0 \mathrm{~nm}$ to $20 \mathrm{~nm}$ and the number of pores between $2.0 \mathrm{~nm}$ and 5.0 $\mathrm{nm}$ was relatively low. Whereas for KF-1500, the number of pores between $2.0 \mathrm{~nm}$ and 5.0 was very large, resulting in large mesopore volume, which contributed to extended the break point time for the adsorption of toluene. The adsorption of toluene appeared to be affected largely by the capillarity condensation phenomenon by mesopores in addition to the micropore filling. In fact, there is slight hysteresis on the adsorption isotherm of KF-1500, providing evidence of the existence of mesopores.

The breakthrough curves of both ACFs in Fig. 2 show drastic "S" shapes due to the break points and became equivalent to the initial concentration soon after. As mentioned above, this is due to the capillary condensation and micropore filling of toluene with a narrow mass transfer zone. This drastic "S" shape indicates that the adsorption has progressed very rapidly, thereby reaching the theoretical adsorption capacity of the adsorbents. In such a case, the maximum adsorption capacity $\left(\mathrm{W}_{\mathrm{e}}\right)$ can be obtained from the adsorption amount of $\mathrm{C} / \mathrm{C}_{\mathrm{o}}=0.5$. In Fig. 2, the adsorption times at $\mathrm{C} / \mathrm{C}_{\mathrm{o}}=0.5$ were $72 \mathrm{~min}$ and $243 \mathrm{~min}$, respectively. Thus, when the initial concentration of toluene was $200 \mathrm{ppm}$ and the air flow rate was maintained at $2 \mathrm{~L} / \mathrm{min}$, the adsorption amount of toluene by MD-1100 ACF at the break point (61 min) was $45.55 \mathrm{mg} / \mathrm{g}$-acf and the maximum adsorption capacity at $\mathrm{C} / \mathrm{C}_{\mathrm{o}}=0.5$ was $53.77 \mathrm{mg} / \mathrm{g}$ acf. However, those of KF-1500 ACF were $171.8 \mathrm{mg} / \mathrm{g}$-acf and $181.5 \mathrm{mg} / \mathrm{g}$-acf, respectively. Therefore, the adsorption capacity of toluene by MD-1100 at the break point was $84.7 \%$ of the maximal adsorption capacity, whereas the adsorption capacity by KF-1500 at the break point was $94.7 \%$ of the maximal adsorption capacity. Thus, the adsorption efficiencies of the two ACFs were very high. On the other hand, the initial toluene concentration of $200 \mathrm{ppm}$ in air is converted into $821.43 \mathrm{mg} / \mathrm{m}^{3}$ by the following Eq. (B):

$$
\frac{m g}{m^{3}}=p p m \times \frac{\text { Molecular weight }}{22.4}
$$

Baek et al. [6] and Kim and Chang [7] also reported that the

Table 3. Adsorption characteristics of KF-1500 and MD-1100

\begin{tabular}{ccccc} 
ACF & $\begin{array}{c}\text { Specific surface } \\
\text { area }\left(\mathrm{m}^{2} / \mathrm{g}\right)\end{array}$ & Total pore volume $\left(\mathrm{cm}^{3} / \mathrm{g}\right)$ & Micropore $\left(\mathrm{cm}^{3} / \mathrm{g}\right)$ & Average pore diameter $(\mathrm{nm})$ \\
KF-1500 & 1690 & 0.7388 & 0.6032 & 1.75 \\
MD-1100 & 1090 & 0.4640 & 0.1356 & 1.70 \\
\hline
\end{tabular}

ACF: activated carbon fiber. 
breakthrough curves of toluene according to an ACF packed bed displayed similar rapid patterns of a narrow mass transfer zone, as in the result of this experiment, whereas $\mathrm{AC}$ took a long time to form a plateau of breakthrough curves upon toluene adsorption by an $\mathrm{AC}$ packed bed given the numerous macropores in $\mathrm{AC}$, which gives rise to diffusion resistance in the mass transfer before the adsorptive reaches the internal meso or micropores. Such an explanation is equivalent to the study of Dubinin [14], Huang et al. [15] and others. Baek et al. [6] reported that it was possible to obtain a maximum adsorption capacity of $370 \mathrm{mg} / \mathrm{g}$-acf when passing toluene vapor of $100 \mathrm{ppm}$ at $0.5 \mathrm{~L} / \mathrm{min}$ through an 0.03 g ACF packed bed. This was approximately twice that in this experiment, thereby displaying a substantially better adsorption capacity of toluene. However, it is difficult to compare their results with the results of this experiment directly due to the different experimental conditions, only showing that the adsorption capacity of toluene by ACF is quite promising. Kim and Chang [7] also reported th at the break point time can be substantially increased under several advantageous conditions; however, he did not suggest the toluene adsorption quantity per ACF. Son et al. [4] did not mention the adsorption quantity, reporting instead that the toluene adsorbed on ACF was mostly desorbed at approximately $90^{\circ} \mathrm{C}$, while $\mathrm{AC}$ cannot match this desorption rate of toluene.

\subsection{Toluene adsorption capacity with a dif- ferent packing density}

Fig. 5 shows the breakthrough curves of toluene with different packing densities of MD-1100 ACFs. From Table 1, experiment (1) was performed at a packing density of $0.1779 \mathrm{~g} / \mathrm{m}^{3}$ by filled up $2.2 \mathrm{~g} \mathrm{MD}-1100$ to the height of $70 \mathrm{~mm}$ of a $15-\mathrm{mm}$ internal diameter bed, experiment (3) was performed at a density of 0.0889 $\mathrm{g} / \mathrm{m}^{3}$ by filling up to $2.2 \mathrm{~g}$ while increasing the height of $140 \mathrm{~mm}$, and experiment (4) filled up to $4.4 \mathrm{~g}$ with a height of $140 \mathrm{~mm}$ and adjusted the packing density until it was equal to that in experiment (1).

All breakthrough curves show an "S" shape after the break point and all quickly reach the initial concentration. Comparing

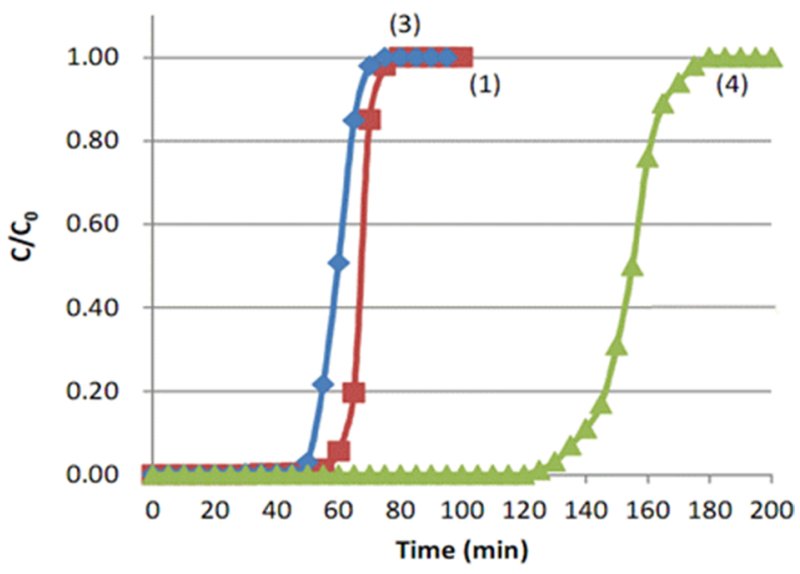

Fig. 5. Breakthrough curves of toluene on MD-1100 with different packing amounts and densities at $25^{\circ} \mathrm{C}, \varphi=15 \mathrm{~mm}, \mathrm{Q}=2 \mathrm{~L} / \mathrm{min}$, and $\mathrm{C}_{\mathrm{o}}=200$ ppm, (1) $2.2 \mathrm{~g}, 70 \mathrm{~mm}, 0.1779 \mathrm{~g} / \mathrm{cm}^{3}$, (3) $2.2 \mathrm{~g}, 140 \mathrm{~mm}, 0.0889 \mathrm{~g} / \mathrm{cm}^{3}$, and (4) $4.4 \mathrm{~g}, 140 \mathrm{~mm}, 0.1779 \mathrm{~g} / \mathrm{cm}^{3}$. the result of (3) with that of (1), the break point time decreased to $53 \mathrm{~min}$ from $61 \mathrm{~min}$ as the packing height increased. The maximum toluene adsorption capacity $\left(\mathrm{W}_{\mathrm{e}}\right)$ corresponding to $\mathrm{C} / \mathrm{C}_{\mathrm{o}}=$ 0.5 , was $62 \mathrm{~min}$, which was 0.86 times that of experiment (1). It is believed that an increase in the packing height with same amount of packing gives rise to a channeling effect due to the insufficient contact between adsorbents and adsorptives. Therefore, it is recommended that an appropriate packing density of adsorbents is determined through different packing density experiments. Comparing the result of (4) with that of (1), the break point time increased to $128 \mathrm{~min}$. In particular, the maximum toluene adsorption capacity $\left(\mathrm{W}_{\mathrm{e}}\right)$ corresponding to $\mathrm{C} / \mathrm{C}_{\mathrm{o}}=0.5$, was $154 \mathrm{~min}$, which was 2.14 times larger than that of experiment (1). Therefore, the break point time and the maximum adsorption capacity can be increased by increasing the packing height with the same packing density. This increased capacity is due to the reduced ratio of the length of the unused bed (LUB), resulting in the increase of the actual length of the adsorption bed height. The LUB can be calculated by the following Eq. (C):

$$
L U B=L\left(1-\frac{W_{b}}{W_{e}}\right)
$$

Here, $W_{e}$ is the maximum adsorption capacity and $W_{b}$ is the adsorption amount from the break point. LUB in experiment (1) was $10.7 \mathrm{~mm}$. This indicates that the theoretical length of the used bed was $59.3 \mathrm{~mm}$. In experiment (4), the length of the unused bed was longer than (1) at $23.7 \mathrm{~mm}$. The theoretical LUB of experiment (4) would also be $10.7 \mathrm{~mm}$ and the actual length of the used bed was $129.3 \mathrm{~mm}$ if experiment (4) had been carried out as it was in experiment (1); consequently, the break point $\left(\mathrm{W}_{\mathrm{b}}\right)$ time would become $133 \mathrm{~min}$. It is believed that the reduced actual break point time of 128 min was caused by ununiformed packing adsorbents when increasing the bed height. Kim and Chang [7] also reported that the break point of toluene adsorption in a non-woven ACF packing bed would appear slow when increasing the packing height and reducing the flow velocity.

\subsection{Toluene adsorption capacity with a dif- ferent bed diameter}

Fig. 6 shows the breakthrough curves of toluene adsorption through the MD-1100 ACF packing bed with different diameters. From Table 1, the experiment (1) was performed at a packing density of $0.1779 \mathrm{~g} / \mathrm{m}^{3}$ by filling up to $2.2 \mathrm{~g}$ MD- 1100 with a height of $70 \mathrm{~mm}$ of a $15-\mathrm{mm}$ internal diameter bed, and experiment (5) was performed at the packing density of $0.0889 \mathrm{~g} / \mathrm{m}^{3}$ by filling to $2.2 \mathrm{~g}$ with the height of $35 \mathrm{~mm}$ of a $30-\mathrm{mm}$ internal diameter bed. Both breakthrough curves also show an "S" shape after the break point, quickly reaching the initial concentration, as in the other conditions. Comparing the result of (5) with (1), the break point time decreased to $45 \mathrm{~min}$ from $61 \mathrm{~min}$ as the bed diameter increased. This means that the adsorption efficiency can be decreased by increasing the bed diameter. There may be a channeling flow of air which gives rise to insufficient contact between the ACF surface and toluene as in the case of an extended bed height with a low density. The maximum toluene adsorption capacity $\left(\mathrm{W}_{\mathrm{e}}\right)$ corresponding to $\mathrm{C} / \mathrm{C}_{\mathrm{o}}=0.5$ was $52 \mathrm{~min}$, which was $72.2 \%$ of that of experiment (1). If the packing density equals $0.1779 \mathrm{~g} / \mathrm{m}^{3}$ by filling the $30 \mathrm{~mm}$ bed diameter to $2.2 \mathrm{~g}$, the height would be $17.5 \mathrm{~mm}$. In 


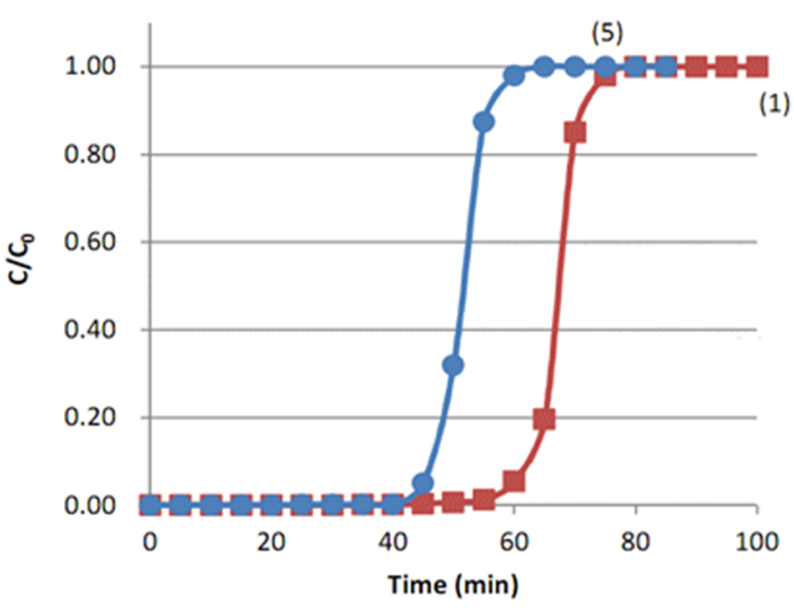

Fig. 6. Breakthrough curves of toluene on activated carbon fiber (MD1100) with different diameters of the packing bed: $Q=2 \mathrm{~L} / \mathrm{min}, \mathrm{C}_{0}=200$ ppm, $M=2.2 \mathrm{~g}$, (1) $\varphi=15 \mathrm{~mm}, 70 \mathrm{~mm}$ and (5) $\varphi=35 \mathrm{~mm}, 35 \mathrm{~mm}$.

this case, the ratio of the used bed height to the unused bed height will decrease compared to experiment (1), and the adsorption efficiency can be decreased. Therefore, for the efficient adsorption of toluene through the ACF packing bed, the bed diameter can be small and the packing height can be high by increased the packing density.

\subsection{Toluene adsorption capability of different bed temperatures}

Fig. 7 shows the breakthrough curves of toluene adsorption on ACF at different bed temperatures. When the control chamber temperature is changed, the toluene vapor concentration also changes. Experiment (1) was performed at $25^{\circ} \mathrm{C}$, and the toluene concentration which can be supplied to the packing bed was controlled at $200 \mathrm{ppm}$. Experiment (6) was performed at $35^{\circ} \mathrm{C}$ while being controlled to $400 \mathrm{ppm}$. $400 \mathrm{ppm}$ toluene in vapor measured $1642.86 \mathrm{mg} / \mathrm{m}^{3}$ according to Eq. (C). The break point time in experiment (6) was $39 \mathrm{~min}$, which was far reduced from $61 \mathrm{~min}$ in experiment (1) with an increase in the toluene concentration. The toluene adsorption capacity $\left(\mathrm{W}_{\mathrm{b}}\right)$ at this time was $58.25 \mathrm{mg} / \mathrm{g}$-acf. The break point time corresponding to $\mathrm{C} / \mathrm{C}_{\mathrm{o}}=0.5$ was $48 \mathrm{~min}$. Thus, the maximum adsorption capacity $\left(\mathrm{W}_{\mathrm{e}}\right)$ at this point was $71.69 \mathrm{mg} / \mathrm{g}$-acf. This value was greater than that $(53.77 \mathrm{mg} / \mathrm{g}$ acf) of experiment (1) due to nearly doubled initial concentration. However, the maximum adsorption capacity increased by only $23 \%$ when doubling the supplying concentration. It is believed that the adsorption mechanism can be determined by the Langmuir equation and that the toluene adsorption by ACF can be effective particularly at a low concentration. If the concentration of VOCs in a newly delivered automobile is maintained less than $200 \mathrm{ppm}$, they can be removed in a relatively short period of time with an ACF filter. Kouichi and Shinichi [2] reported that the VOC concentration in an automobile increases exponentially with an increase in the indoor temperature. The toluene concentrations were 150,720 and $2670 \mu \mathrm{g} / \mathrm{m}^{3}$ at indoor temperatures of 20,40 and $60^{\circ} \mathrm{C}$, respectively. Therefore, reducing the indoor temperature is also recommended by frequently recycling the indoor air

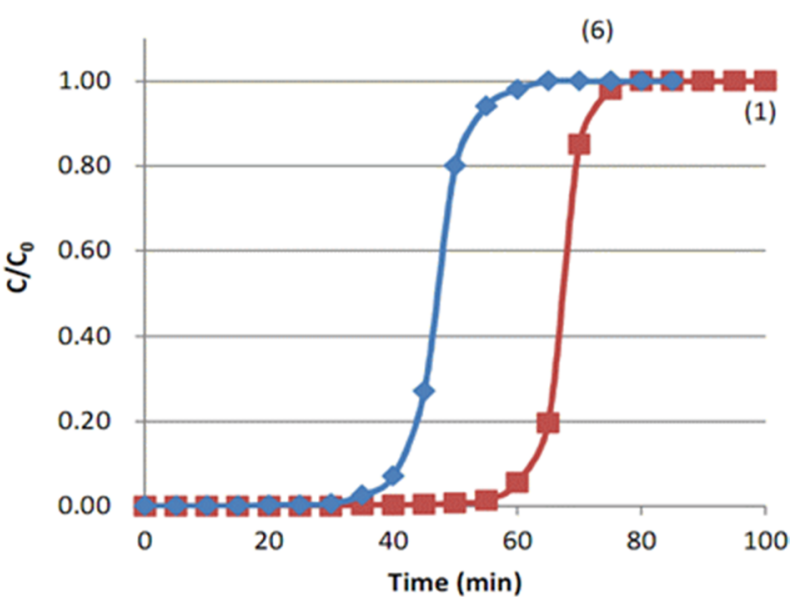

Fig. 7. Breakthrough curves of toluene on activated carbon fiber (MD$1100)$ at $(1) 25^{\circ} \mathrm{C}(\mathrm{Co}=200 \mathrm{ppm})$, and (6) $35^{\circ} \mathrm{C}\left(\mathrm{C}_{\mathrm{o}}=400 \mathrm{ppm}\right), \mathrm{Q}=2 \mathrm{~L} /$ $\min , \mathrm{M}=2.2 \mathrm{~g}$.

with fresh air while driving an automobile in addition to the use of an ACF filter.

\subsection{Adsorption behaviors in an ACF packed} bed

There are many different methods to predict the VOC adsorption behaviors of an $\mathrm{AC}$ packed bed. However, there are few reports related to the adsorption behaviors of an ACF packed bed. In this study, Yoon and Nelson's Eq. (D), which has been very frequently applied among several equations related to an AC adsorption bed, was applied to predict the breakthrough curve and adsorption behaviors of an ACF packed bed.

$$
\ln \left(\frac{C_{x}}{C_{o}-C_{x}}\right)=\frac{k_{v} C_{o}}{\rho_{B} W_{e}} t-\frac{k_{v} L}{V_{L}}
$$

Here, the inlet toluene concentration $\mathrm{C}_{\mathrm{o}}$ is $821.43 \mathrm{mg} / \mathrm{m}^{3}(200$ ppm), ACF packing density $\rho_{B}$ is $0.1779 \mathrm{~g} / \mathrm{cm}^{3}$, the packing length $L$ is $70 \mathrm{~mm}$, and the superficial velocity $V_{L}$ is $18.875 \mathrm{~cm} / \mathrm{sec}(2$ $\mathrm{L} / \mathrm{min} \varphi=15 \mathrm{~mm}$ ). $\mathrm{W}_{\mathrm{e}}$ is the dynamic (maximum) adsorption capacity and $\mathrm{k}_{\mathrm{v}}$ is the velocity constant. In Fig. 8, the straight line shows the relationship between $\ln \left(\frac{C_{x}}{C_{0}-C_{x}}\right)$ and time (t). From the slope of $\left(\frac{k_{v} C_{0}}{\rho_{B} W_{e}}\right)$ and the intercept $\left(\frac{k_{v} L}{V_{L}}\right)$ of a straight line, the dynamic adsorption capacity $\mathrm{W}_{\mathrm{e}}$ and the velocity constant $\mathrm{k}_{\mathrm{v}}$ can be obtained. As a result, a slope of $0.475 \mathrm{~min}^{-1}$ and an intercept of -31.55 were calculated by a regression analysis. Thus, values of $\mathrm{W}_{\mathrm{e}}$ $=49.52 \mathrm{mg} / \mathrm{g}$-acf and $\mathrm{k}_{\mathrm{v}}=85 \mathrm{sec}^{-1}$ were obtained. In a comparison, the dynamic adsorption capacity obtained in this method and the maximum adsorption capacity of $53.77 \mathrm{mg} / \mathrm{g}$-acf as obtained from $\mathrm{C} / \mathrm{C}_{\mathrm{o}}=0.5$, as shown in Fig. 3, good agreement was obtained at an error tolerance of $8 \%$. Thus, the equation of Yoon and Nelson can be utilized for predicting dynamic adsorption behaviors. Inversely, various breakthrough curves can be predicted by applying the dynamic adsorption capacity and the velocity constant under different experimental conditions. Cheng et al. [16] reported that 


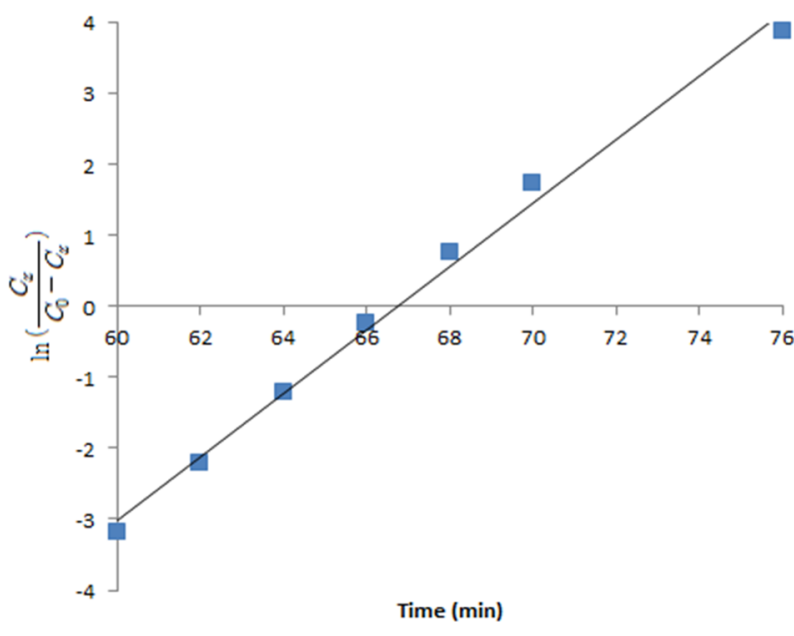

Fig. 8. Time dependence of the breakthrough concentration of toluene on activated carbon fiber (MD-1100).

the maximum adsorption capacity of toluene on a viscose-based ACF was $57.73 \mu \mathrm{g} / \mathrm{cm}^{3}$-acf, which was 13.3 times higher than that in this work. It appears to be excessively high. The inlet toluene concentration of their work was $17.36 \mathrm{mg} / \mathrm{m}^{3}(=4227 \mathrm{ppm})$. This is too high a concentration to obtain reasonable results from a $15 \mathrm{mg}$ packed bed. They did not mention how large the surface area of the ACF was. However, they confirmed the excellent toluene adsorption capacity of the ACF. Das et al. [17] reported a breakthrough of toluene on ACF $\left(1000-1700 \mathrm{~m}^{2} / \mathrm{g}\right)$ using an inlet concentration of $10000 \mathrm{ppm}$ through a $5 \mathrm{~g}$ ACF packed bed (with a $2.5 \mathrm{~cm}$ diameter). They also obtained very sharp " $\mathrm{S}$ "-shaped curves, as in our results; however they did not mention the maximum adsorption capacity, only mentioning the mass transfer coefficients and rate constants. The rate constant $\left(k_{v}\right)$ depends on the adsorbent type; thus, it would be possible to examine the change in the rate constant by conducting experiments with several types of VOCs.

\section{Conclusion}

In a batch experiment, an ACF non-woven filter shows far better adsorption capacities for VOCs (formaldehyde, toluene and benzene, all of which are generated from the interior materials of automobiles) in comparison with those of a PP non-woven filter and a $\mathrm{PP}+\mathrm{AC}$ combination filter currently used in automobiles. Unde a continuous flow of toluene vapor through an ACF packed bed, all of the breakthrough curves show a rapid "S" shape after a long extended break point in spite of the different experimental conditions due to the narrow mass transfer zone and short unused bed length. In particular, the ACF prepared with a pore size of 2-5 $\mathrm{nm}$ shows excellent adsorption capacity by micro-filling of micropores plus the capillary condensation mechanism of the mesopores. The Yoon and Nelson equation, which was derived from $\mathrm{AC}$ and which is frequently used for predictions of dynamic adsorption behaviors, was also applied to investigate the adsorption behaviors of an ACF packed bed. Therefore, ACF prepared with a pore size distribution of 2-5 $\mathrm{nm}$ can be a promising filter for the removal of VOCs in newly delivered automobiles.

\section{References}

[1] Kim CN, Lee YG. A study of the concentration change of volatile organic compounds: VOCs by using mock-up test. Korean J AirCond Refrig Eng, 17, 487 (2005).

[2] Kouichi T, Shinichi T. Measurement of VOC occurs in a car interior. J Soc Heat Air-Cond Sanit Eng Jpn, 12, 27 (2009).

[3] Lee IH, Yoo JH, Kim MG. Evaluation of volatile organic compounds emitted from door-trim armrest using micro chamber and 20 L static chamber. Anal Sci Technol, 24, 290 (2011). http:// dx.doi.org/10.5806/AST.2011.24.4.290.

[4] Son MS, Kim SD, Woo KJ, Park HJ, Seo MC, Lee SH, Ryu SK. Adsorption characteristics of three-components volatile organic compounds on activated carbonacaceous adsorbents. Korean Chem Eng Res, 44, 669 (2006).

[5] Ryu SK. Porosity of activated carbon fibers. High Temp High Press, 22, 345 (1990).

[6] Baek GH, Kim JS, Jang HT, Kim HW, Kim HJ, Cha WS. Adsorption/desorption properties of VOCs on activated carbon fiber. J Korea Acad-Ind Coop Soc, 12, 2439 (2011).

[7] Kim SG, Chang YR. Adsorption characteristics of toluene in the adsorption bed packed with activated carbon fiber. J Korean Soc Atmos Environ, 24, 220 (2008).

[8] Byun YS, Chung SW, Yoo SO, Yu MH, Jun DH. Adsorption and desorption performance of toluene and IPA for ACF and activated carbon. Appl Chem, 13, 65 (2009).

[9] Park JH, Byun JH, Hwang JH, Ji JH. Adsorption and desorption characteristics of ACF (activated carbon fiber) filter to gaseous benzene. Proceedings of the 41st Meeting of Korean Society for Atmospheric Environment, 529 (2006).

[10] Moon HS, Kim JS, Kim IS. A study on the PM2.5 concentration in the car in Jeonju downtown. J Korean Soc Environ Eng, 35, 717 (2013).

[11] Korean Standards Association, KS I 2218: Detector tube type gas measuring instruments (2009).

[12] Yoon YH, Nelson JH. Application of gas adsorption kinetics. I. A theoretical model for respirator cartridge service life. Am Ind Hyg Assoc J, 45, 509 (1984). http://dx.doi org/10.1080/15298668491400197.

[13] McCabe WL, Smith JC, Harriott P. Unit Operations of Chemical Engineering. 7th ed., McGraw-Hill, Boston, MA, 847 (2005).

[14] Dubinin MM. A study of the porous structure of active carbons using a variety of methods. Q Rev Chem Soc, 9, 101 (1955). http:// dx.doi.org/10.1039/QR9550900101.

[15] Huang ZH, Kang F, Liang KM, Hao J. Breakthrough of methyethylketone and benzene vapors in activated carbon fiber beds. J Hazard Mater, 98, 107 (2003). http://dx.doi.org/10.1016/S03043894(02)00284-4.

[16] Cheng T, Jiang Y, Zhang Y, Liu S. Prediction of breakthrough curves for adsorption on activated carbon fibers in a fixed bed. Carbon, 42 3081 (2004). http://dx.doi.org/10.1016/j.carbon.2004.07.021.

[17] Das D, Gaur V, Verma N. Removal of volatile organic compound by activated carbon fiber. Carbon, 42, 2949 (2004). http://dx.doi org/10.1016/j.carbon.2004.07.008. 